\title{
Maternal-fetal Rhesus (Rh) factor incompatibility in Arar, northern Saudi Arabia
}

Raghad Mubarak Aljuhaysh ${ }^{1}$, Nagah Mohamed Abo El-Fetoh ${ }^{2,3}$, Malak Ibrahim Alanazi ${ }^{1}$, Afaf Shuaib Albaqawi ${ }^{1}$, Wafa Mohammed Alanazi ${ }^{1}$, Najah Salah Alanazi ${ }^{1}$, Reham Muqbil Alanazi ${ }^{1}$, Atheer Mutab Alanazi ${ }^{4}$, Eiman Mohammad Alnemer ${ }^{1}$, Rahma Abdulhadi Alenezi ${ }^{4}$, Tasleem Khoudier Alabdullatif ${ }^{1}$, Rehab Abdallah Alanazi ${ }^{1}$, Samiyah Sarhan Alanazi ${ }^{1}$, Kawthar Saeed Alsultan ${ }^{1}$, Ibtisam Matan Alanazi ${ }^{4}$, Duaa Sami Alsunayni ${ }^{1}$

${ }^{1}$ Intern, Faculty of Medicine, Northern Border University, Arar, Kingdom of Saudi Arabia

${ }^{2}$ Associate Professor of Public Health and Community Medicine, Faculty of Medicine, Northern Border University, Arar, Kingdom of Saudi Arabia

${ }^{3}$ Sohag College of Medicine, Sohag University, Egypt

${ }^{4}$ Medical Student, Northern Border University, Arar, Kingdom of Saudi Arabia

\section{Type of article: Original}

\begin{abstract}
Background and aim: $\mathrm{Rh}$ isoimmunization still contributes to the neonatal morbidity and mortality due to nonimmunization, under-immunization, and in rare cases, false Rh typing. The main objective of this study was to determine the prevalence of $\mathrm{Rh}$ incompatibility, mothers' knowledge about Rh incompatibility, mothers' knowledge about anti-D immunoglobulin and to show the pregnancy outcome of Rh negative mothers.

Methods: A cross-sectional study was carried out at the Maternity and Children Hospital in Arar city from November 2016 to May 2017. All pregnant mothers attending the Maternity and Children Hospital for pregnancy follow up or delivery, during the study period were studied. Data were collected by means of personal interview with the sampled population using a researcher-made questionnaire covering the needed data. Data were analyzed by SPSS version 16, using descriptive statistics and Chi-Square test.

Results: Of the studied mothers, $23 \%$ were Rh negative. Only $38 \%$ of the studied mothers had knowledge about $\mathrm{Rh}$ incompatibility, $68.5 \%$ had knowledge about anti-D and 51\% had knowledge about time of administration of anti D. Considering pregnancy outcome; $55 \%$ of the delivered babies needed incubation after delivery, $23.3 \%$ of those babies were born to Rh negative mothers. However, $6.7 \%$ of the incubated children died after incubation ( $47.8 \%$ of them belong to Rh negative mothers).

Conclusion: About a quarter of the mothers in the studied population were Rh negative. Mothers had a low level of knowledge about Rh incompatibility and anti-D immunoglobulin and its administration. Health education sittings are needed to increase public awareness about this important issue.

Keywords: Rh negative; Mothers; Arar city; Knowledge; Rh incompatibility; Anti-D immunoglobulin
\end{abstract}

\section{Introduction}

Hemolytic disease of the newborn (HDN) is considered as a disease whose basis is accelerated immune destruction of child erythrocytes that are bound to IgG antibodies of maternal origin. These antibodies are directed against antigens of the father's origin, which are present in the children's erythrocytes and that the mother's immune system recognizes as foreign antigens (1). The incidence of $\mathrm{Rh}$ disease in a population depends on predominance of rhesus negative. About (15\%) of the white population has an $\mathrm{RhD}$ negative blood type. Population data reported that the incidence of $\mathrm{RhD}$ negativity is highest among Basques (36\%). Seven percent of black people have this blood type. Less than $1 \%$ of the Native American and Asian populations have this phenotype (2). Anti-D should be given within 72 hours after birth to reduce the risk of $\mathrm{RhD}$ complications in rhesus negative women who have given birth to a rhesus positive infant. However, the evidence on the optimal dose is limited (3). A study in Baghdad reported that;

\section{Corresponding author:}

Raghad Mubarak Aljuhaysh, Faculty of Medicine, Northern Border University, Arar, Kingdom of Saudi Arabia. Tel.: +966546166676, Email: raghadaljuhish@gmail.com

Received: August 02, 2017, Accepted: September 15, 2017, Published: December 2017

iThenticate screening: September 15, 2017, English editing: October 26, 2017, Quality control: November 02, 2017 (C) 2017 The Authors. This is an open access article under the terms of the Creative Commons Attribution-NonCommercialNoDerivs License, which permits use and distribution in any medium, provided the original work is properly cited, the use is non-commercial and no modifications or adaptations are made. 
the highest prevalence rate among the holders of blood group (A) was 30.1\%, followed by holders of blood group (f) which was $29.6 \%$, then the holders of blood type (b) $27.2 \%$, and finally the holders of blood type (AB) at $13.1 \%$. The study found that the proportion of negative blood type was $4.2 \%$, including $3.6 \%$ among females and $4.75 \%$ for males (4). A previous study in Nigeria (5) showed that the level of knowledge of maternal-fetal blood incompatibility of expectant mothers was low (only 39\% correct response) and barely an average of 56\% for positive attitudes, only $42 \%$ of the respondents had ever done the test. Another study in the same field which was conducted in India reported; a total of 90 neonates were born to Rh-negative mothers, of which 70\% (63) had the Rh-positive blood group and 30\% had the Rh negative blood group. Of these 63 neonates, 48 (76.2\%) had hyperbilirubinemia and 43 neonates $(68.3 \%)$ had significant hyperbilirubinemia. In a study by Bondagji NS, Rhesus negative blood group was reported in $7.5 \%$ cases. There were 424 cases reported as $\mathrm{Rh}$ antibody positive with an alloimmunization prevalence of $1.8 \%$ in the studied population, and $23.6 \%$ among $\mathrm{Rh}$ negative women. Perinatal mortality rate was 250 per 1000 in alloimmunized pregnancies (6). Local population based studies on male and female volunteers from Saudi Arabia revealed that the prevalence of $\mathrm{Rh}$ negative blood group in the eastern region of Saudi Arabia is $8 \%$ and in southwest Saudi Arabia, it is 7.2\% (7, 8). There is a major paucity in the literature regarding the estimated prevalence of $\mathrm{Rh}$ negativity and mothers' knowledge about $\mathrm{Rh}$ incompatibility and anti-D immunoglobulin and the pregnancy outcome of $\mathrm{Rh}$ negative mothers among pregnant women in Saudi Arabia, particularly in the northern region. So, we carried out our study. The main objective of this study is to determine the prevalence of $\mathrm{Rh}$ incompatibility, mothers' knowledge about Rh incompatibility, mothers' knowledge about anti-D immunoglobulin and to show the pregnancy outcome of Rh negative mothers.

\section{Material and Methods}

\subsection{Study type and Setting}

A cross-sectional study was carried out at the Maternity and Children Hospital in Arar city, the capital of the Northern Province of Saudi Arabia, during the period from 1 November 2016 to 30 May 2017. All pregnant mothers attending the Maternity and Children Hospital for pregnancy follow up or delivery during the study period, were studied.

\subsection{Sampling}

The sample size was calculated using the sample size equation: $n=z^{2}-p(1-p) / e^{2}$, considering the prevalence of $R h$ negative mothers in Arar is 50\%, target population more than 1000 , and study power $95 \%$. A total of 343 Saudi females aged (20-45) years were included in the study. We performed systematic random sampling technique on every $4^{\text {th }}$ mother.

\subsection{Data collection}

Data were collected by means of personal interview with the sampled population using a researcher-made questionnaire covering the following items:

1) Socio-demographic characteristics including age, educational status and consanguinity.

2) Mother's and father's blood group and $\mathrm{Rh}$.

3) Questions regarding the mothers' knowledge about $\mathrm{Rh}$ incompatibility, follow up of pregnancy, administration of prophylactic and after delivery anti $\mathrm{D}+$.

4) Questions whether the mother think's their baby will need an incubator after delivery, and questions about the general status of the baby after incubation.

\subsection{Ethical consideration}

Before starting data collection, ethical approval was obtained from the Research Ethics Committee of the Faculty of Medicine, Northern Border University. During data collection stage, informed consent was secured from each participant. The questionnaires used in data collection were anonymous, and confidentiality of data was assured.

\subsection{The statistical analysis}

The statistical analysis was carried out using SPSS version 16 (SPSS Inc., Chicago, Illinois, USA). Sample characteristics were summarized as numbers and percentages for categorical variables. Chi-Square test was used for comparing qualitative variables. A 5\% level was chosen as a level of statistical significance in all statistical tests used in the study. 
http://www.ephysician.ir

\section{Results}

According to the study, $47.8 \%$ of participants were aged between 20-24 years old, 27.4\% were aged 25-30 and $15.7 \%$ were aged between 31-40 years old (Table 1). Regarding educational level; about two thirds of the studied population were highly educated, $19.5 \%$ reached secondary school while $5.8 \%$ were illiterate. Consanguinity was positive in $41.4 \%$ of the studied participants. Table 2 shows mothers and fathers' blood groups and Rh. Blood group A was found in $39 \%$ of mothers (30\% were Rh positive and 9\% were negative), 33.8\% had blood group O (27.7\% positive and $6.1 \% \mathrm{Rh}$ negative), $16.6 \%$ had blood group $\mathrm{B}(12.8 \% \mathrm{Rh}$ positive and $3.8 \% \mathrm{Rh}$ negative) and only $10.5 \%$ had blood group $\mathrm{AB}(6.4 \% \mathrm{Rh}$ positive and $4.1 \% \mathrm{Rh}$ negative). Regarding father's blood groups; $36.7 \%$ had blood group A, 28.9\% were blood group O, 19.2\% blood group B and 15.2\% with blood group AB. A total of $79 \%$ of fathers were Rh positive. Table 3 illustrates the mothers' knowledge about Rh incompatibility, follow up of pregnancy, administration of prophylactic and after delivery anti D. A total number of 131 mothers had knowledge about $\mathrm{Rh}$ incompatibility. About 235 mothers had regular follow up of pregnancy, while 72 mothers had irregular follow up and only 36 mothers had no follow up of pregnancy. Of the studies sample, 146 mothers had previous repeated abortion or premature labor. Regarding knowledge about administration of prophylactic anti D; 235 mothers had knowledge about it, while only 175 mothers had knowledge about administration of anti D after delivery. Table 4 shows the condition of the delivered baby in Rh negative and positive mothers. About $55 \%$ of the delivered babies needed incubation after delivery, $23.3 \%$ of those babies were born to Rh negative mothers. Of the incubated children, $6.7 \%$ died after incubation ( $47.8 \%$ of them belonged to Rh negative mothers).

Table 1. Age group of the mother, educational level and consanguinity between parents among the studied mothers, Arar, KSA $(\mathrm{n}=343)$

\begin{tabular}{|l|l|l|l|}
\hline \multicolumn{2}{|l|}{ Variables } & $\mathrm{n}$ & $\%$ \\
\hline Age of mothers (year) & $20-24$ & 164 & 47.8 \\
\cline { 2 - 4 } & $25-30$ & 94 & 27.4 \\
\cline { 2 - 4 } & $31-40$ & 54 & 15.7 \\
\cline { 2 - 4 } & $40+$ & 31 & 9.0 \\
\hline \multirow{5}{*}{ Educational level } & Illiterate & 20 & 5.8 \\
\cline { 2 - 4 } & Read and write & 28 & 8.2 \\
\cline { 2 - 4 } & Preparatory & 22 & 6.4 \\
\cline { 2 - 4 } & Secondary & 67 & 19.5 \\
\cline { 2 - 4 } & University or more & 206 & 60.1 \\
\hline Consanguinity & No & 201 & 58.6 \\
\cline { 2 - 4 } & Yes & 142 & 41.4 \\
\hline
\end{tabular}

Table 2. Studied mothers' and fathers' blood groups and Rh, Arar, KSA

\begin{tabular}{|l|l|l|l|l|l|l|l|l|}
\hline \multicolumn{2}{|c|}{ ABO group } & \multicolumn{2}{l|}{ Rh positive } & \multicolumn{2}{l|}{ Rh negative } & \multicolumn{2}{l|}{ Total } \\
\cline { 3 - 10 } & & $\mathrm{n}$ & $\%$ & $\mathrm{n}$ & $\%$ & $\mathrm{n}$ & $\%$ \\
\hline Mother's blood group and Rh & $\mathrm{A}$ & 103 & 30.0 & 31 & 9.0 & 134 & 39.0 \\
\cline { 2 - 10 } & $\mathrm{AB}$ & 22 & 6.4 & 14 & 4.1 & 36 & 10.5 \\
\cline { 2 - 10 } & $\mathrm{B}$ & 44 & 12.8 & 13 & 3.8 & 57 & 16.6 \\
\cline { 2 - 9 } & $\mathrm{O}$ & 95 & 27.7 & 21 & 6.1 & 116 & 33.8 \\
\cline { 2 - 9 } & Total & 264 & 77.0 & 79 & 23.0 & 343 & 100.0 \\
\hline Father's blood group and Rh & $\mathrm{A}$ & 97 & 28.3 & 29 & 8.5 & 126 & 36.7 \\
\cline { 2 - 9 } & $\mathrm{AB}$ & 33 & 9.6 & 19 & 5.5 & 52 & 15.2 \\
\cline { 2 - 9 } & $\mathrm{B}$ & 52 & 15.2 & 14 & 4.1 & 66 & 19.2 \\
\cline { 2 - 9 } & $\mathrm{O}$ & 89 & 25.9 & 10 & 2.9 & 99 & 28.9 \\
\hline & Total & 253 & 79.0 & 72 & 21.0 & 343 & 100.0 \\
\hline
\end{tabular}


Table 3. Knowledge of the mothers about Rh incompatibility, Follow up of pregnancy and administration of prophylactic anti D among the studied mothers.

\begin{tabular}{|c|c|c|c|c|c|c|c|}
\hline \multirow{2}{*}{\multicolumn{3}{|c|}{ Parameters }} & \multicolumn{2}{|l|}{$\mathrm{Rh}$} & \multirow[t]{2}{*}{ Total } & \multirow{2}{*}{$\begin{array}{l}\text { Chi- } \\
\text { Square }\end{array}$} & \multirow{2}{*}{$\begin{array}{l}\mathrm{p}- \\
\text { value }\end{array}$} \\
\hline & & & Negative & Positive & & & \\
\hline \multirow{6}{*}{$\begin{array}{l}\text { Mothers' knowledge about RH } \\
\text { incompatibility }\end{array}$} & \multirow[t]{2}{*}{ No } & $\mathrm{n}$ & 44 & 168 & 212 & \multirow[t]{6}{*}{1.624} & \multirow[t]{6}{*}{0.127} \\
\hline & & $\%$ & $20.8 \%$ & $79.2 \%$ & $100.0 \%$ & & \\
\hline & \multirow[t]{2}{*}{ Yes } & $\mathrm{n}$ & 35 & 96 & 131 & & \\
\hline & & $\%$ & $26.7 \%$ & $73.3 \%$ & $100.0 \%$ & & \\
\hline & \multirow[t]{2}{*}{ Total } & $\mathrm{n}$ & 79 & 264 & 343 & & \\
\hline & & $\%$ & $23.0 \%$ & $77.0 \%$ & $100.0 \%$ & & \\
\hline \multirow[t]{8}{*}{ Follow up of pregnancy } & \multirow{2}{*}{$\begin{array}{l}\text { Irregular } \\
\text { follow up }\end{array}$} & $\mathrm{n}$ & 17 & 55 & 72 & \multirow[t]{8}{*}{0.579} & \multirow[t]{8}{*}{0.748} \\
\hline & & $\%$ & $23.6 \%$ & $76.4 \%$ & $100.0 \%$ & & \\
\hline & \multirow[t]{2}{*}{ No follow up } & $\mathrm{n}$ & 10 & 26 & 36 & & \\
\hline & & $\%$ & $27.8 \%$ & $72.2 \%$ & $100.0 \%$ & & \\
\hline & \multirow{2}{*}{\begin{tabular}{|l|} 
Regular follow \\
up
\end{tabular}} & $\mathrm{n}$ & 52 & 183 & 235 & & \\
\hline & & $\%$ & $22.1 \%$ & $77.9 \%$ & $100.0 \%$ & & \\
\hline & \multirow[t]{2}{*}{ Total } & $\mathrm{n}$ & 79 & 264 & 343 & & \\
\hline & & $\%$ & $23.0 \%$ & $77.0 \%$ & $100.0 \%$ & & \\
\hline \multirow{6}{*}{$\begin{array}{l}\text { Previous repeated abortions and/or } \\
\text { premature labor }\end{array}$} & \multirow[t]{2}{*}{ No } & $\mathrm{n}$ & 37 & 160 & 197 & \multirow[t]{6}{*}{4.170} & \multirow[t]{6}{*}{0.021} \\
\hline & & $\%$ & $18.8 \%$ & $81.2 \%$ & $100.0 \%$ & & \\
\hline & \multirow[t]{2}{*}{ Yes } & $\mathrm{n}$ & 42 & 104 & 146 & & \\
\hline & & $\%$ & $28.8 \%$ & $71.2 \%$ & $100.0 \%$ & & \\
\hline & \multirow[t]{2}{*}{ Total } & $\mathrm{n}$ & 79 & 264 & 343 & & \\
\hline & & $\%$ & $23.0 \%$ & $77.0 \%$ & $100.0 \%$ & & \\
\hline \multirow[t]{6}{*}{ Administration of prophylactic anti D } & \multirow[t]{2}{*}{ No } & $\mathrm{n}$ & 20 & 70 & 90 & \multirow[t]{6}{*}{0.885} & \multirow[t]{6}{*}{0.478} \\
\hline & & $\%$ & $22.2 \%$ & $77.8 \%$ & $100.0 \%$ & & \\
\hline & Yes & $\mathrm{n}$ & 59 & 194 & 253 & & \\
\hline & & $\%$ & $23.3 \%$ & $76.7 \%$ & $100.0 \%$ & & \\
\hline & Total & $\mathrm{n}$ & 79 & 264 & 343 & & \\
\hline & & $\%$ & $23.0 \%$ & $77.0 \%$ & $100.0 \%$ & & \\
\hline Anti $\mathrm{D}$ after delivery or abortion & No & $\mathrm{n}$ & 33 & 128 & 161 & 2.370 & 0.306 \\
\hline & & $\%$ & $20.5 \%$ & $79.5 \%$ & $100.0 \%$ & & \\
\hline & Yes & $\mathrm{n}$ & 46 & 136 & 175 & & \\
\hline & & $\%$ & $24.6 \%$ & $75.4 \%$ & $100.0 \%$ & & \\
\hline & Total & $\mathrm{n}$ & 79 & 264 & 343 & & \\
\hline & & $\%$ & $23.0 \%$ & $77.0 \%$ & $100.0 \%$ & & \\
\hline
\end{tabular}

Table 4. The relationship between condition of the delivered baby in RH negative and positive mothers

\begin{tabular}{|c|c|c|c|c|c|c|c|}
\hline \multirow{2}{*}{\multicolumn{3}{|c|}{ Condition of the delivered baby }} & \multicolumn{2}{|l|}{$\mathrm{Rh}$} & \multirow[t]{2}{*}{ Total } & \multirow[t]{2}{*}{ Chi-Square } & \multirow[t]{2}{*}{ p-value } \\
\hline & & & Negative & Positive & & & \\
\hline \multirow{6}{*}{$\begin{array}{l}\text { Need for incubator after } \\
\text { delivery }\end{array}$} & \multirow[t]{2}{*}{ No } & $\mathrm{n}$ & 35 & 119 & 154 & \multirow[t]{6}{*}{0.015} & \multirow[t]{6}{*}{0.514} \\
\hline & & $\%$ & $22.7 \%$ & $77.3 \%$ & $100.0 \%$ & & \\
\hline & \multirow[t]{2}{*}{ Yes } & $\mathrm{n}$ & 44 & 145 & 189 & & \\
\hline & & $\%$ & $23.3 \%$ & $76.7 \%$ & $100.0 \%$ & & \\
\hline & \multirow[t]{2}{*}{ Total } & $\mathrm{n}$ & 79 & 264 & 343 & & \\
\hline & & $\%$ & $23.0 \%$ & $77.0 \%$ & $100.0 \%$ & & \\
\hline \multirow[t]{6}{*}{ Status after incubation } & \multirow[t]{2}{*}{ Died } & $\mathrm{n}$ & 11 & 12 & 23 & \multirow[t]{6}{*}{8.549} & \multirow[t]{6}{*}{0.006} \\
\hline & & $\%$ & $47.8 \%$ & $52.2 \%$ & $100.0 \%$ & & \\
\hline & \multirow{2}{*}{$\begin{array}{l}\text { Alive and } \\
\text { healthy }\end{array}$} & $\mathrm{n}$ & 68 & 252 & 320 & & \\
\hline & & $\%$ & $21.2 \%$ & $78.8 \%$ & $100.0 \%$ & & \\
\hline & \multirow[t]{2}{*}{ Total } & $\mathrm{n}$ & 79 & 264 & 343 & & \\
\hline & & $\%$ & $23.0 \%$ & $77.0 \%$ & $100.0 \%$ & & \\
\hline
\end{tabular}




\section{Discussion}

$\mathrm{Rh}$ isoimmunization still contributes to neonatal morbidity and mortality in the world due to non-immunization, under-immunization and in rare cases, false Rh typing (9). This study was conducted to determine the prevalence of $\mathrm{Rh}$ incompatibility and to show the pregnancy outcome of $\mathrm{Rh}$ negative mothers in Arar, Saudi Arabia. Our study findings of mothers' blood groups were as follows; blood group A was found in $39 \%$ of mothers, $33.8 \%$ had blood group $\mathrm{O}, 16.6 \%$ had blood group $\mathrm{B}$ and only $10.5 \%$ had blood group $\mathrm{AB}$. Of the total number of mothers, there was $23 \% \mathrm{Rh}$ negative mothers. In Izetbegovic $\mathrm{S}$. et al study (1). Only $14 \%$ of the studied mothers were $\mathrm{Rh}$ negative (42\% blood group A, 33\% blood group O, 17\% blood group B and $8 \%$ AB blood group). Another study found that; the highest prevalence blood group was group A $(30.1 \%)$, followed by $\mathrm{O}(29.6 \%)$ then $\mathrm{B}(27.2 \%)$ and finally came $\mathrm{AB}(13.1 \%)$ and the prevalence of Rh-negative among the study group was (4.2\%) (3.6\% among females and 4.75 among males) (4). A study in southwestern Nigeria reported that Rh positive women were 563 (94.5\%), and Rhnegative women constituted (5.5\%). Of the Rh negative women, $(45.5 \%)$ were of blood group O, while (27.3\%), $(18.2 \%),(9.1 \%)$ were of blood group A, B, and AB, respectively (10). This is still within the prevalence range of 4.6\% and 5.7\% for negative $\mathrm{Rh}$ found in the general women's population at the Baptist Medical Centre and the State General Hospital, respectively, both in Ogbomoso, by Bakare et al. in the year 2000 (11). Although; a prevalence of $3.3 \%$ was found by Bakare et al. in the general population in Ogbomoso, $60 \%$ of them were females. The $5.4 \% \mathrm{RhD}$ negative prevalence in this study is comparable to the $5 \%$ from Ibadan (12), also located in southwestern Nigeria as is Ogbomoso, but a higher figure than $4.5 \%$ from Enugu, southeastern Nigeria (10). However, results of the current study showed that, women had low level of knowledge regarding maternal-fetal blood incompatibility (about 38\% of the studied mothers had knowledge about Rh incompatibility). This result is consistent with the findings of other studies $(5,13)$ which found mean score for correct response about knowledge of $\mathrm{Rh}$ incompatibility $=39 \%$. Regarding knowledge of the studied mothers about anti-D, we found that; $68.5 \%$ of the mothers had knowledge about it, while only $51 \%$ of the mothers had knowledge about administration of prophylactic anti D after delivery. A study in Singapore reported that; only $49.1 \%$ of the participants (27/55) had adequate knowledge of the guidelines on anti-D prophylaxis. The remaining $40.0 \%$ and $10.9 \%$ of the participants had inadequate and poor knowledge, respectively (12). Considering pregnancy outcome; our study reported that, $55 \%$ of the delivered babies needed incubation after delivery, $23.3 \%$ of those babies were born to Rh negative mothers, $6.7 \%$ of the incubated children died after incubation (47.8\% of them belong to Rh negative mothers). In the southwestern Nigerian study (10); there were (3.0\%) stillbirths, and (9.1\%) asphyxiated babies who were admitted into the special care baby unit; one of these severely asphyxiated babies died, while the other two had blood transfusions for neonatal jaundice. A multicentric systematic review by Bhutani et al. reported $0.36 \%$ of Rh disease with $24 \%$ risk for mortality, $13 \%$ risk for kernicterus and $11 \%$ for stillbirths. Three-quarters of mortality was reported from sub-Saharan Africa and South Asia (13). Walker et al., in their large series of $\mathrm{Rh}$ pregnancies reported that $33 \%$ of the neonates required no treatment (12).

\section{Conclusions}

Of the studied mothers in Arar, northern Saudi Arabia, there was 23\% Rh negative. More than a third had knowledge about Rh incompatibility, about two thirds had knowledge about anti-D and about half had knowledge about time of administration of anti D. Rhesus alloimmunization represents an avoidable direct cause for perinatal morbidity and mortality in our population, so health education sittings are needed to increase the awareness of the public about this important issue. Future large-scale community and hospital based research concerning the Rhesus alloimmunization problem must be conducted to help in improving the pregnancy outcome and decreasing the perinatal morbidity and mortality in our population.

\section{Acknowledgments:}

The authors would like to thank the staff members at the Maternity and Children Hospital in Arar city, in addition to all colleges who helped us in different steps of data collection and preparation of the manuscript. Authors also acknowledge the personnel who conducted the data entry and statistical analysis of the research data.

\section{Conflict of Interest:}

There is no conflict of interest to be declared.

Authors' contributions:

All authors contributed to this project and article equally. All authors read and approved the final manuscript. 


\section{References:}

1) Izetbegovic S. Occurrence of $\mathrm{ABO}$ and $\mathrm{RhD}$ Incompatibility with Rh Negative Mothers. Mater Sociomed. 2013; 25(4): 255-8. doi: 10.5455/msm.2013.25.255-258. PMID: 24511269, PMCID: PMC3914752.

2) Mourant AE, Kopec AC, Domaniewska-Sobczak K. The distribution of the human blood groups and other biochemical polymorphisms. 2nd ed. London: Oxford University Press; 1976.

3) Nasif Raif E. The incidence of blood groups in Lebanese. Lebanon med j. 2005; 11(6): 346-9.

4) Hayyawi AH, Suhail HJ, Selman WS. Rh Incompatibility: Prevalence, Knowledge and Attitude for Premarital Test Couples. Kufa Journal For Nursing Sciences. 2014; 4(3).

5) Kio JO, Agbede CO, Oroniyi FA. Assessing Expectant Mothers' Knowledge and Practices Regarding Maternal-Fetal Blood Incompatibility: Evidence from Ogun State, Nigeria. Greener Journal of Epidemiology and Public Health. 2016; 4(2): 013-019. doi: 10.15580/GJEPH.2016.2.100216152.

6) Bondagji NS. Rhesus alloimmunization in pregnancy. A tertiary care center experience in the Western region of Saudi Arabia. Saudi Med J. 2011; 32(10): 1039-45. PMID: 22008924.

7) Bashwari LA, Al-Mulhim AA, Ahmad MS, Ahmed MA. Frequency of ABO blood groups in the Eastern region of Saudi Arabia. Saudi Med J. 2001; 22: 1008-12. PMID: 11744976.

8) Sarhan MA, Saleh KA, Bin-Dajem SM. Distribution of ABO blood groups and Rhesus factor in Southwest Saudi Arabia. Saudi Med J. 2009; 30: 116-9. PMID: 19139784.

9) Holburn AM, Prior D. The UK national external quality assessment scheme in blood group serology. ABO and D grouping and antibody screening 1982-1983. Clin Lab Haematol. 1986; 8(3): 243-56. PMID: 3093139.

10) Samson AA, Hajara Titilope BA. Prevalence of Rhesus D-negative blood type and the challenges of Rhesus D immunoprophylaxis among obstetric population in Ogbomoso, Southwestern Nigeria. Annals of Tropical Medicine and Public Health. 2016; 9(1): 12-5.

11) Bakare AA, Azeez MA, Agbolade JO. Gene frequencies of $\mathrm{ABO}$ and rhesus blood groups and haemoglobin variants in Ogbomoso, South-West Nigeria. Afr J Biotechnol. 2006; 5(3): 224-9.

12) Wee WW, Kanagalingam $D$. The use of anti-D immunoglobulins for rhesus prophylaxis: audit on knowledge and practices among obstetricians. Singapore Med J. 2009; 50(11): 1054. PMID: 19960158.

13) Fikree F, Karim MS, Midhet F, Berendes HW. Causes of reproductive age mortality in low socioeconomic settlements of Karachi. J Pak Med Assoc. 1993; 43: 208-12. 